\title{
Aproximación al enfoque jurídico del Informe Final de la Comisión de la Verdad y Reconciliación
}

\author{
Javier Ernesto Ciurlizza Contreras
}

\section{El informe final de la CVR: una aproximación multidisciplinaria a los crímenes y violaciones a los derechos humanos}

El 28 de agosto del 2003, la Comisión de la Verdad y Reconciliación (CVR) entregó su informe final en el que daba cumplimiento al mandado conferido mediante decreto supremo emitido por el gobierno de transición y posteriormente ampliado por el actual gobierno. ${ }^{1}$ En dicho informe, la CVR presentó un amplio estudio respecto de las causas de la violencia, el comportamiento de los actores políticos e institucionales, los hechos de violencia que le correspondió recoger, las secuelas que produjo en personas y colectividades, así como un conjunto de recomendaciones orientadas a afirmar la memoria histórica del país, cimentar la justicia, propiciar un proceso integral de reparaciones a las víctimas de la violencia y sentar las bases de la reconciliación nacional. ${ }^{2}$

El estudio sobre el que se basó el trabajo de la CVR tomó en consideración las múltiples facetas que presenta uno de los períodos más complejos y, al mismo tiempo, trágicos de nuestra historia. La CVR concluyó que

* Director del Instituto de Democracia y Derechos Humanos de la Pontificia Universidad Católica del Perú. Ex Secretario Ejecutivo de la Comisión de la Verdad y Reconciliación. Profesor de la Facultad de Derecho y la Maestría en Política Jurisdiccional de la PUCP.

1 Decreto supremo 065-2001-PCM y 101-2001-PCM. Mediante decreto supremo 0782003-PCM se puso término administrativo a las labores de la CVR y se organizó el proceso de transferencia documental $y$ administrativa de su patrimonio.

2 El informe puede ser consultado en la página: <www.cverdad.org.pe>. Hay hasta dos versiones oficiales del informe final: nueve tomos y un CD-ROM con anexos, que fue entregado por los comisionados el 31 de agosto del 2003 y una versión abreviada titulada: "Hatun Willakuy" («el gran relato») que fue elaborada por la Comisión de Transferencia, por autorización de la CVR. 
aproximadamente 69 mil personas habían muerto o desaparecido como consecuencia directa de crímenes y violaciones a los derechos humanos, $75 \%$ de las cuales tenían el quechua como lengua materna. ${ }^{3}$

Aun cuando la violencia sacudió al país entero, sus efectos se concentraron especialmente en la población andina y de las comunidades nativas de la selva peruana. Es decir, la mayor parte de las víctimas forma parte de la población secularmente discriminada y más pobre del país. Esta situación explica, en parte, la indiferencia que aún hoy aqueja a muchos peruanos y al Estado respecto a personas que han sido considerados ciudadanos de segunda categoría, prescindibles herramientas de proyectos políticos de diversa índole.

La primera conclusión que podemos encontrar en el informe de la CVR se refiere a las graves y persistentes fracturas sociales, culturales y económicas que estuvieron en la base del conflicto armado que afectó al país. Comprobar estas brechas que dividen a los peruanos no constituyó un mero ejercicio académico, redundante de múltiples estudios que ya existen sobre la materia, sino principalmente explicar el sustento del término «reconciliación». Para la CVR, la reconciliación que el país necesita tiene muy poco que ver con el reencuentro de dos bandos en conflicto, y más bien con la integración del ciudadano con el Estado y los ciudadanos entre sí, generando mayores cuotas de "ciudadanía" entre todos los peruanos. ${ }^{4} \mathrm{El}$ acceso de los peruanos y peruanas a elecciones periódicas se muestra notoriamente insuficiente como condición sustantiva de la democracia. Esta, cabalmente comprendida, denota un proceso de toma de decisiones en el que las mayorías nacionales perciban que participan en las ventajas y riesgos de los procesos sociales y económicos. Este proceso no existió en el Perú de 1980 y dificilmente existe en la actualidad.

Enfocar la violencia conforme a las brechas anotadas representó para la CVR un considerable esfuerzo analítico que no podía ser asumido por una sola disciplina o con personas que provinieran de una única experiencia profesional. En los primeros meses de su funcionamiento, comisionados y profesionales de la CVR discutieron las características metodológicas que debería orientar el proceso de esclarecimiento de los hechos y, por ende, la naturaleza de sus hallazgos y recomendaciones. Al respecto, aun cuandio pueda resultar algo esquemática la discusión, esta se centró en dos aproximaciones posibles al estudio de la violencia: ${ }^{5}$

Véase el tomo l, capítulo 3 del Informe Final: "Rostros y perfiles de la violencia».

- La expresión propositiva de este enfoque de la reconciliación se puede encontrar en las reformas institucionales propuestas por la CVR.

5 Las discusiones sobre los enfoques metodológicos de la investigación de la CVR se produjeron entre octubre del 2001 y febrero del 2002. La distinción que señalamos se 
(a) La violencia ocurrida en el Perú solo puede ser comprendida y analizada si se toma en cuenta el itinerario histórico nacional, a partir del cual el contexto en el que se produce un crimen es más importante que el crimen en sí mismo. A esta aproximación se le denominó, en su momento, la "verdad histórica».

(b) Los hechos que debe estudiar la CVR constituyen crímenes y violaciones a los derechos humanos, por lo que resulta pertinente y fundamental estudiar los "casos" en los que existen víctimas y perpetradores. El contexto se construye en función de la demostración de la responsabilidad política y penal de los presuntos responsables. A este enfoque se le nominó como la «verdad jurídica».

Naturalmente, ambas aproximaciones tenían muchos más puntos en común que aparentes desencuentros. Las personas que provenían de experiencias de análisis social y de la ciencia política preferían una mirada integradora del proceso de la violencia, mientras que aquellos que tenían una formación legal o que provenían del campo de las organizaciones de derechos humanos buscaban cimentar los casos como unidad de análisis esencial. Al final, la integración de ambas perspectivas produjo una productiva síntesis de dos maneras de mirar fenómenos similares. En lo que todos estábamos de acuerdo era en que ninguna disciplina, de manera aislada, podía brindar una mirada integral y satisfactoria de un proceso que tenía mucho de contexto histórico, pero también rostros visibles en peruanos y peruanas que murieron o desaparecieron como consecuencia de actos concretos de otros peruanos y peruanas.

La respuesta analítica que está incluida en el Informe Final proviene de un amplio ejercicio multidisciplinario, en el cual todos aprendimos mucho de aquellas materias que no dominábamos. Uno de los aspectos más notables del trabajo fue la comprobación de que la mera agregación de los enfoques no era suficiente para hablar de multidisciplinaridad, sino que era necesario la aplicación de conceptos y categorías que permitieran hacer dialogar a abogados con sociólogos, antropólogos, historiadores, politólogos y filósofos.

La integración de las diversas disciplinas encontró un fértil campo en muchos terrenos que le correspondió estudiar a la CVR. Abordamos en este ensayo algunos de estos terrenos, pero desde una mirada jurídica. Sin perjuicio de ese desarrollo, es importante poner de relieve otros en los que la propuesta de la CVR (tanto en el análisis como en los aspectos propositivos) recogieron lo mejor de cada enfoque profesional.

(a) El diagnóstico del comportamiento de los actores institucionales. En particular, el análisis de la conducta de la administración de justicia incluyó un pormenorizado 
análisis de la legislación y estructura del Poder Judicial y el Ministerio Público durante los veinte años que le correspondió analizar a la CVR. El informe final nos habla, jurídicamente, de la manera en que la legislación y la práctica judicial oscilaron de una abdicación de funciones tanto en la sanción de los crímenes terroristas como en aquellos casos de violaciones a los derechos humanos hacia una legislación draconiana que hizo tabla rasa del debido proceso legal y que anuló las posibilidades de la independencia judicial en la década de los noventa. Esta explicación se ve complementada y reforzada con el análisis del sistema de administración de justicia como un actor institucional propio, o agente en términos sociológicos, que asume decisiones y, por tanto, responsabilidades que no pueden ser meramente atribuidas al marco legal que guía su práctica. En este sentido, un estricto y exclusivo análisis jurídico habría, quizás, orientado el estudio de la CVR solo hacia los aspectos externos del sistema, mientras que la sociología nos permite incluir al Poder Judicial y al Ministerio Público como entidades que toman decisiones y se hacen cargo de estas, por acción o por omisión.

(b) El plan integral de reparaciones incluyó un conjunto de medidas en el campo individual, colectivo, simbólico y sectorial (educación y salud). Estas propuestas no hubieran sido posibles de articular si la CVR no resolvía el aparente dilema de la víctima individual y la víctima colectiva. Generalmente, para los juristas no existe un daño colectivo reconocible que no esté taxativamente reconocido en la ley como un daño posible (es decir, que la ley reconozca a un sujeto colectivo como poseedor de derechos). Por otro lado, para los científicos sociales puede resultar más importante reconstruir una comunidad o enfocar el "daño social» antes que atender a las personas individualmente consideradas. ${ }^{6}$ Estas dos percepciones encuentran cabida en la propuesta de reparación, que involucra la dimensión social del daño, pero no olvida que los derechos que fueron vulnerados fueron individuales y personales.

Analizados estos dos campos, queremos concentrarnos, en el resto de este ensayo, en algunos terrenos en los que las propuestas iniciales partieron básicamente de un enfoque jurídico de la violencia, mirada que fue progresivamente enriquecida con el aporte de otras disciplinas. En particular, nos referiremos a la construcción del concepto de "patrón sistemático" de violación a los derechos humanos, los criterios de atribución de responsabilidades y las propuestas orientadas a reformar al sistema judicial.

6 Para la CVR resultó imposible aplicar, en el tiempo disponible, una herramienta analítica que describiera con propiedad el denominado "daño social». No solo por lo impreciso del término sino porque la única manera en que se puede hacer un estudio sobre daños colectivos sería un censo nacional, estrategia que resultó imposible cuando el INEI informó que un censo específicamente diseñado con ese propósito excedía las posibilidades existentes del presupuesto. El Programa de Apoyo al Repoblamiento realizó (antes y durante la (VR), un "censo por la paz", que muestra las percepciones de dirigentes de comunidades campesinas y nativas respecto a este daño. 


\section{Los patrones de violaciones sistemáticas}

Por lo general, en el derecho se reconocen las funciones de atribuir derechos y obligaciones a sujetos y relacionar dichos sujetos de diversas maneras. La articulación de los sujetos da sentido a un sistema jurídico en tanto organización de normas sustantivas y procesales, y en tanto construcción de instituciones. La función del derecho es, valga la redundancia en este caso, estrictamente normativa. Tradicionalmente, la prescripción jurídica se ha considerado contrapuesta a la descripción analítica de las ciencias sociales. Al ser la ciencia del deber ser, el derecho se abstrae de consideraciones sobre lo que es.

No obstante, el derecho incluye, dentro de sus herramientas, categorías analíticas que permiten clasificar y ordenar. La función científica de calificación en el derecho cumple el atributo de señalar qué tipo de obligaciones y derechos corresponde a qué tipo de sujetos. Al clasificar hechos, el derecho proporciona un argumento coherente a eventos que, de manera aislada, pueden ser considerados como fenómenos autárquicos, sin conexión lógica con otros eventos. El proceso de agregación de hechos en tipos encuentra su concreción más acabada en el derecho penal, en donde los tipos penales permiten englobar diversos hechos cometidos bajo diversas modalidades, pero que comparten un bien jurídico similar. Esta función clasificadora del derecho, paradójicamente, obliga a la prescripción a describir, aun cuando este ejercicio sea estrictamente funcional (se hace en función de encuadrar hechos en normas jurídicas específicas). La descripción normativa nos permite integrar la realidad en categorías analíticamente diferenciadas.

Este ejercicio estuvo presente en la construcción del Informe Final de la CVR. Este órgano recibió 16.985 testimonios de víctimas o testigos de crímenes o violaciones a los derechos humanos, además de realizar más de 18 audiencias públicas y conducir estudios en profundidad y reconstruir historias de regiones específicas. Toda esta información fue procesada en un sistema de información, del cual la base de datos constituyó un elemento central, mas no único. Para transformar los datos en un sistema, fue preciso adoptar categorías y clasificadores. De otra manera, la CVR hubiera ofrecido al país únicamente una lista abierta de hechos, sin ningún tipo de criterio organizador. La labor de sistematización de la información corresponde, en su ejecución, a profesionales preparados para administrar grandes cantidades de información. Sin embargo, los clasificadores o tipos fueron elaborados en gran medida por abogados. Para agrupar crímenes y violaciones, la CVR recurrió al derecho no solo como prescripción sino como fuente de categorías descriptivas. Esta descripción que realizó la CVR se denominó, en su fase más intensa, "patrones de crímenes y violaciones a los derechos humanos". 
Esta categoría no fue inventada por la CVR. Se ha usado de manera extensa en el derecho internacional de los derechos humanos, particularmente en las decisiones que adoptan los mecanismos de Naciones Unidas. ${ }^{7}$ Últimamente, se le ha incorporado como criterio diferenciador del crimen de lesa humanidad. Así, el Estatuto de la Corte Penal Internacional incorpora la existencia de un patrón sistemático como prerrequisito para la existencia de tal crimen. En este caso, estamos frente a un concepto claramente usado a la manera en que el Derecho Penal describe los tipos penales: agrupando hechos aparentemente inconexos para demostrar cierta intensidad y sistematicidad que le da una cualidad distinta a un delito aislado. El tipo de crimen de lesa humanidad requiere, entonces, la existencia de patrones.

Se discute la propiedad de usar el término "patrones" pues resulta quizá una traducción impropia del término en inglés patterns. Aun cuando esta observación es lingüísticamente correcta, el término ha entrado en el lenguaje de los sistemas internacionales de protección a los derechos humanos y las traducciones oficiales de Naciones Unidas no han encontrado un mejor término en español por el momento, por lo que nos sentimos con licencia para aplicarlo en este ensayo.

Teniendo en cuenta el tiempo y los recursos disponibles, el informe final se concentra en nueve patrones en la perpetración de crímenes y violaciones a los derechos humanos:

(a) asesinatos y masacres,

(b) desapariciones forzadas,

(c) ejecuciones arbitrarias,

(d) tortura y tratos crueles, inhumanos o degradantes,

(e) violencia sexual contra la mujer,

(f) violación del debido proceso,

(g) secuestro y toma de rehenes,

(h) violencia contra niños y niñas; $y$,

(i) violación de derechos colectivos.

Mediante la construcción de estos tipos, la CVR ofrece en su informe una descripción pormenorizada de los hechos que fueron materia de su mandato, incluyendo la presentación del marco jurídico aplicable, la descripción de los crímenes cometidos y las conclusiones correspondientes. El

ONU, Comisión de Derechos Humanos, Resolución 8 (XXIII), del 16 de marzo de 1967; Consejo Económico y Social, resoluciones 1235 y 1503, del 6 de junio de 1967 y 27 de mayo de 1970, respectivamente. En el mismo sentido, la Comisión Interamericana de Derechos Humanos se refiere al concepto de "patrón sistemático" en su informe 56/99 del 13 de abril de 1999, párrafos 65 y 68 . 
trabajo presentado resalta la importancia de generalizar lo más posible en cuanto se refiere a eventos aparentemente aislados. No todo crimen o violación calzará dentro de estos tipos, pero su concreción permite afirmar la existencia o no de un crimen de lesa humanidad, así como atribuir responsabilidades a jefes y superiores

\section{3. ¿Quién viola derechos humanos?}

Históricamente, el concepto de derechos humanos se origina como resultado directo de procesos en los que el individuo afirma su autonomía personal respecto de la autoridad del soberano. Desde la Carta Magna hasta las declaraciones del siglo XvIII, el esfuerzo por incluir derechos inalienables del ser humano ha estado en conexión con la dialéctica entre un Estado todopoderoso y amenazador $y$ un individuo que afirma su derecho a la seguridad (Hobbes), a la libertad y la propiedad (Locke), al cumplimiento de normas sociales de carácter contractual (Rousseau) o a la promoción de su dignidad (Kant).

El derecho internacional público acoge como una rama específica al derecho internacional de los derechos humanos, y le extrapola sus conceptos y categorías. De esta manera, los modernos tratados de derechos humanos reconocen similares fuentes y condiciones que todos los tratados regulados en la Convención de Viena sobre el Derecho de los Tratados de 1969 (por ejemplo, la aplicación del «sistema de fuentes» planteado en el artículo 38 del Estatuto de la Corte Internacional de Justicia). Un tratado es un acuerdo entre sujetos de derecho internacional, mediante el cual se establecen derechos y obligaciones (sinalagma contractual). Normalmente, el objeto y fin de un tratado internacional consiste en fijar condiciones y prestaciones recíprocas entre dos sujetos de naturaleza equivalente, o cuya relación es formalmente horizontal.

Sin embargo, el propio derecho internacional de los derechos humanos ha reconocido que, en el caso de los tratados de derechos humanos, no existe tal sinalagma contractual, pues el objeto y fin del tratado es la protección del ser humano y no el otorgamiento de prestaciones recíprocas entre dos Estados soberanos. Aquí los publicistas hacen, a mi criterio, un salto en trampolín para justificar la excepcionalidad. Se acude al criterio del derecho internacional general o a la particular naturaleza de los derechos humanos para argumentar que un tratado (un contrato) no supone prerrogativas particulares para una de las partes, por lo que no puede esa parte (ese Estado) incumplir dicho tratado en función del incumplimiento de otra de las partes. 
El argumento de los expertos es correcto desde un punto de vista formal. Faúndez afirma que, en el caso de los derechos humanos, existe un efecto vertical. Similar posición se puede leer en la ortodoxia del campo de los derechos humanos. Por efecto vertical, se entiende que, mediante los derechos humanos, los Estados asumen las obligaciones y las personas ejercen los derechos. Contrario sensu, los Estados no pueden tener derechos y las obligaciones que tienen las personas no son óbice para afirmar la primacía de sus derechos. El llamado "efecto vertical» es incorporado de manera neta en el derecho internacional de los derechos humanos al construir procedimientos y órganos que tienen por finalidad esencial verificar el cumplimiento por parte del Estado de una obligación internacionalmente establecida. Este es un argumento suficiente para señalar que los individuos, o los grupos no estatales (como las organizaciones subversivas que usan el terrorismo) no pueden ser denunciados jurídicamente ante la Comisión Interamericana de Derechos Humanos. Sin embargo, el peligro está en extrapolar una razón jurídico-procesal a una razón jurídica sustantiva.

Los procedimientos internacionales de protección de los derechos humanos fueron establecidos bajo la presunción, aún hoy vigente, que los Estados son los únicos autorizados para obligarse en el plano internacional en materia de derechos humanos. Pero esa presunción no es correcta cuando hablamos del concepto de derechos humanos. Peces Barba llama a este proceso la «humanización del Derecho o del orden normativo" al indicar que la persona se convierte en el fin último de la organización social. Por supuesto que es el fin del Estado, pero también lo es de la sociedad y de otras personas.

Desde un punto de vista sustantivo, la pertinencia del concepto de derechos humanos se deriva de la posesión de dichos derechos, no de quien puede vulnerarlos. Por ello, el informe de la CVR precisa que la violación de los derechos humanos puede ser cometida por cualquiera, incluyendo otros individuos o agrupaciones no estatales. No es válido, dice el informe final, que por razones jurídico-procesales que dan cuenta del órgano o procedimiento pertinente, se haga distingos al momento de hablar de qué nomen iuris corresponde a un acto que vulnera derechos personales. Aun cuando la norma que establece la comisión señala que debía contribuir al esclarecimiento de graves "crímenes y violaciones a los derechos humanos", la CVR integra ambos conceptos y los funde en uno solo. La consecuencia no es solo un ejercicio retórico o gramatical, pues cada víctima tiene derecho a la justicia, a la verdad y a la reparación con prescindencia del agente que perpetró la violación de sus derechos humanos.

En el Perú, en donde más de la mitad de estos actos fueron perpetrados por miembros del Partido Comunista del Perú-Sendero Luminoso (PCP- 
SL), está afirmación tiene una trascendencia especial. Sin menoscabar en lo más mínimo la responsabilidad que le cabe al Estado, la CVR sindica responsabilidades concretas a la dirección nacional del PCP-SL, como se detalla a continuación.

\section{La atribución de responsabilidades: en la búsqueda del «hombre de atrás»}

La contribución a la justicia pedida en el decreto de creación de la CVR implicó la aplicación de categorías del derecho penal, complementadas por la aplicación simultánea de conceptos provenientes del derecho internacional general. En particular, correspondía a la CVR identificar, en la medida de lo posible, a los presuntos responsables de la comisión de graves crímenes y violaciones a los derechos humanos que, como ha quedado anotado en líneas precedentes, formaban parte de patrones consistentes y prácticas reiteradas.

El derecho penal establece tipos delictivos en función de la responsabilidad individual. Es decir, no puede reclamarse responsabilidad penal de instituciones u organizaciones. Por ello, la responsabilidad sobre hechos específicos siempre tendrá que concretarse en la dimensión personal del presunto perpetrador. Sin embargo, la CVR también consideró responsabilidades políticas y morales de instituciones públicas y, naturalmente, de organizaciones subversivas. Esas responsabilidades son precisadas al momento de evaluar la conducta institucional de aquellos actores públicos que tenían deberes específicos con relación a la violencia que se estudió.

Dicho esto, la responsabilidad por casos específicos debía ser analizada a la luz de los tipos penales existentes en la legislación nacional. De conformidad con el principio de legalidad, establecido en nuestra Constitución y en los tratados internacionales sobre derechos humanos, se supone que ninguna persona puede ser juzgada por hechos que, al momento de su comisión, no constituían delito, teniendo en cuenta que la única aplicación retroactiva del ordenamiento jurídico penal es aquella que resulte más favorable al imputado. Por ello, un primer problema que la CVR tuvo que enfrentar en el ámbito de la responsabilidad penal fue el de las sucesivas modificaciones legales ocurridas en el Código Penal, que fueron introduciendo progresivamente tipos derivados de convenios internacionales suscritos y ratificados por el Perú. Tal fue el caso del delito de desaparición forzada, introducido en 1991, derogado en 1992 y reinstalado pocos meses después. En aplicación estricta del principio de legalidad anotado, cabría suponer que ningún hecho cometido antes de la entrada en vigor del referido 
Código, e incluso aquellos hechos ocurridos en los meses en los cuales el tipo penal no existió, no podría ser considerado como desaparición forzada, sino simplemente como secuestro.

No obstante, a diferencia de otras opiniones recientemente expresadas, ${ }^{8}$ la CVR sostuvo que la desaparición forzada de personas es un delito continuado, pues sus efectos se prolongan en el tiempo hasta la determinación del paradero de la víctima. De similar opinión ha sido el Tribunal Constitucional en su sentencia referida al derecho a la verdad, en la que precisa que no puede oponerse la prescripción a la obligación del Estado de investigar hechos que configuran un delito permanente. ${ }^{9}$ La conclusión de la CVR fue que la tipificación del delito de desaparición forzada no debe atender necesariamente a la ley vigente al momento de la detención de la persona sino a aquella vigente al tiempo de la denuncia e investigación correspondiente. No resulta ni legal ni moralmente válido reducir la entidad de una desaparición forzada a la figura del secuestro simple.

Para la identificación de presuntas responsabilidades individuales, la CVR tomó nota de las peculiares características de los delitos cometidos en el contexto del conflicto armado interno, a saber:

(a) La mayor parte de los crímenes cometidos pertenecen a la caregoría de delitos complejos, ya sea por la pluralidad de víctimas, de perpetradores o de bienes jurídicos vulnerados.

(b) La complejidad delictiva se explica, además, por el hecho de que los actos ilícitos fueron cometidos al interior de determinadas organizaciones. Un argumento recurrente de los presuntos perpetradores ha sido el de la atribución de la responsabilidad a ordenes superiores.

(c) Las organizaciones a las cuales pertenecían o pertenecen los presuntos perpetradores no son de idéntica condición y naturaleza. Se trata de organizaciones subversivas ilegales, por un lado, y de instituciones públicas - reconocidas constitucionalmente- por otro.

8 Ver la interesante investigación de Giovanna Vélez sobre el delito de desaparición forzada de personas, en el que sostiene que, en tanto este hecho no puede tener características de permanencia o continuidad, pues es un delito de comisión instantánea con efectos permanentes, no sería posible la aplicación del tipo penal correspondiente.

9 Sentencia sobre el expediente 2488-2002-HC/TC (Piura). Genaro Villegas Namuche, del 18 de marzo del 2004: "La garantía de la ley previa comporta la necesidad de que, al momento de cometerse un delito, esté vigente una norma penal que establezca una determinada pena. Así, en el caso de delitos instantáneos, la ley penal aplicable será siempre anterior al hecho delictivo. En cambio, en los delitos permanentes, pueden surgir nuevas normas penales, que serán aplicables a quienes en ese momento ejecuten un delito, sin que ello signifique aplicación retroactiva de la ley penal. Tal es el caso del delito de desaparición forzada, el cual, según el artículo III de la Convención Interamericana sobre Desaparición Forzada de Personas, deberá ser considerado como delito permanente mientras no se establezca el destino o paradero de la víctima» (el subrayado es nuestro). 
Esta última característica parte además de la opción estatal que asume la CVR. Este órgano no fue, ni podía ser, un ente neutro que actúa en el contexto de un conflicto armado sostenido entre dos partes moral y legalmente equivalentes. A diferencia de otras experiencias, la peruana se caracterizó por la decisión política de una organización subversiva, de destruir al Estado y construir un modelo social distinto. El Estado al que esta organización buscó destruir no era una dictadura ni un régimen intrínsecamente ilegal. Por el contrario, los tiempos buscados para los primeros actos de violencia subversiva coincidieron a conciencia con el retorno del Perú al régimen democrático. Más allá de las múltiples imperfecciones del sistema democrático, en el Perú rigieron las instituciones democráticas, hubo libertad de expresión, elecciones periódicas y otros elementos que configuran el régimen democrático constitucional.

La CVR consideró que solo podría hacerse excepción del período comprendido entre el 5 de abril de 1992 y finales del mismo año. Durante esos siete meses, el gobierno (que había sido legítimamente elegido) decidió disolver e intervenir los otros poderes del Estado y gobernar por decreto ley por medio del denominado régimen de emergencia y reconstrucción nacional. Al ponerse por encima de la legalidad constitucional, las máximas autoridades de este régimen asumieron plena responsabilidad, sin intermediación posible alguna, respecto a todo acto contrario a los derechos humanos perpetrado en ese período.

Dicho esto, lo pertinente no era entonces analizar la responsabilidad penal individual en casos supuestamente aislados, o siquiera agrupados en patrones. La CVR debió analizar, desde una perspectiva sociológica, la naturaleza de la organización al interior de la cual se cometieron delitos, así como el contexto social y político que explica - aun cuando no siempre justifica- esos hechos.

Similares preguntas se han hecho los penalistas al momento de determinar la manera en que la naturaleza de una organización puede afectar los alcances de la responsabilidad criminal. Claude Roxin inauguró, en la década de los sesenta, esa reflexión, la que ha acompañado célebres procesos judiciales, como el seguido contra Eichmann en Jerusalén, o las juntas militares argentinas en 1983. A cada paso que da, el derecho penal vuelve su mirada hacia aspectos que no pueden ser explicados solo jurídicamente sino a partir de categorías de enfoque multidisciplinario.

Las consecuencias de la naturaleza de los ilícitos, y de las organizaciones al interior de la cual se cometen estos hechos, son respondidas por el derecho penal por medio de la teoría de la autoría y participación. Los grados de relación posible entre una persona individualmente considerada y un acto ilícito han estado en la base de numerosos estudios de dogmática penal. Sin 
entrar en campos que no dominamos, basta describir someramente la manera en que la CVR consideró la aplicación de la autoría y la participación a los hechos que le correspondió estudiar.

La distinción entre autor y partícipe es relativamente sencilla en ilícitos simples. Es autor quien domina objetiva y subjetivamente el hecho, y es participe quien induce o coopera en la comisión de ese delito, cuya realización siempre demanda un autor. Por otro lado, en delitos complejos, la distinción se hace más difícil, pues los hechos son planeados y ejecutados por actores difusos y no siempre identificables. Roxin nos ofrece una respuesta por la teoría de la autoría mediata a través de aparatos organizados de poder. Para su aplicación, se requerirían cuatro elementos concurrentes:

(a) Que se trate de un aparato organizado de poder con una estructura jerárquica rígida.

(b) Que se verifique la fungibilidad efectiva del autor inmediato, lo que implica que la organización tenga una estructura consistente y durable.

(c) Que de la intercambiabilidad del ejecutor directo se derive un control automático para el "hombre de atrás".

(d) Que el aparato de poder se haya desligado del ordenamiento jurídico, optando integralmente por la vía criminal.

A partir de estas consideraciones doctrinales, la CVR refiere su aplicación al estudio de la organización correspondiente, concluyendo lo siguiente:

(a) Todo hecho cometido por un miembro de una organización subversiva, en tanto configura delito y este forma parte de un patrón sistemático, es atribuible a las más altas instancias de la referida organización.

(b) No necesariamente todo delito cometido por un miembro de las fuerzas del orden es atribuible a todos y cada uno de los eslabones de la cadena de mando, en tanto el Estado peruano no puede ser entendido como organización criminal.

(c) No obstante, en las circunstancias y momentos en donde agentes del Estado perpetraron crímenes de manera reiterada y sistemática, y siempre y cuando dichos delitos fueran cometidos en el interior de una organización cerrada y territorialmente organizada para cometer esos delitos, se halla responsabilidad penal en la cabeza de esa organización territorial.

(d) La regla (b) no se aplica en los delitos cometidos en el interior de los destacamentos operativos del Servicio de Inteligencia Nacional que, por lo menos entre 1991 y 1994, perpetraron crímenes con la complicidad abierta de las más altas esferas del poder.

Estas cuatro conclusiones resumen el enfoque contenido en cada uno de los 47 expedientes remitidos por la CVR a la Fiscalía de la Nación el 1 de 
septiembre del 2003, así como los 18 casos enviados a conocimiento directo de la Sala Nacional de Terrorismo. ${ }^{10}$

\section{Epílogo: el Derecho frente a las recomendaciones de la CVR}

La tragedia que vivió el país entre 1980 y el 2000 no se limita a un recuento de las víctimas o a un diagnóstico social de una compleja realidad. Los crímenes y violaciones producidos, las terribles secuelas que hoy enfrentamos y la tendencia hacia la negación que algunos peruanos tienen, son heridas que tardarán muchos años en empezar a cicatrizar. Atendiendo a lo que se vive hoy en otros países que pasaron por experiencias de comisiones de la verdad, las consecuencias políticas de la violencia en el Perú seguirán cobrando, con creces, la indiferencia que hoy le prodiguemos a las recomendaciones de la CVR.

El sistema jurídico y las instituciones que aplican el derecho tienen una seria y amplia responsabilidad en esta tarea. La acción de la violencia tiene orígenes diversos, pero la respuesta de una democracia a esa acción debe partir del régimen democrático y el Estado de Derecho. El derecho nos provee de las suficientes herramientas para enfrentar el pasado y promover la justicia para las miles de víctimas que la esperan.

La agenda es compleja y sin duda de largo plazo. Es fundamental, en primer lugar, que los operadores jurídicos conozcan a cabalidad el informe final de la CVR, así como consideren el diagnóstico multidisciplinario producido a fin de trasladarlo hacia la construcción de hipótesis legales. En segundo lugar, atenuar el extremo formalismo en la aplicación de categorías normativas a fin de evitar que obstáculos jurídicos impidan la realización de la justicia. Naturalmente, ello supone también actuar en estricto acatamiento de principios legales que contienen también derechos humanos. No obstante, el Tribunal Constitucional nos ha dado un ejemplo de la manera en que se afirma la protección de la persona humana como fin último de la investigación judicial (como actividad del Estado), al mismo tiempo que se respetan las garantías judiciales contenidas en la Constitución y el Estado de Derecho.

Finalmente, en el ámbito jurídico, los esfuerzos por integrar el derecho interno con el derecho internacional de los derechos humanos y el derecho internacional humanitario, deben trascender la mera incorporación de nuevos

10 El Estatuto de la Corte Penal Internacional sistematiza la doctrina sobre responsabilidad penal al señalar las reglas de atribución de dicha responsabilidad a jefes y superiores (artículos 25 a 28). 
acuerdos internacionales. Así, deben incorporar un ejercicio creativo de las doctrinas más modernas en estos ámbitos, e incluir, además, los avances de la jurisprudencia y práctica de los sistemas internacionales de protección a los derechos humanos.

El informe de la CVR solo puede ser entendido socialmente como un primer paso hacia la consolidación y, en algunos casos, la construcción de un sistema democrático en el Perú. Los abogados y operadores del derecho tienen un lugar privilegiado en este proceso. Detenerse en este camino solo podrá representar un desgaste adicional de la legitimidad de nuestro sistema político. 